Bull. Mater. Sci., Vol. 20, No. 6, September 1997, pp. 805-815. (O Printed in India.

\title{
Alloy design with the aid of molecular orbital method
}

\author{
MASAHIKO MORINAGA* and HIROSHI YUKAWA \\ Department of Materials Science and Engineering, School of Engineering, Nagoya University, \\ Furo-cho, Chikusa-ku, Nagoya 464-01, Japan

\begin{abstract}
A molecular orbital approach to alloy design has recently made great progress. This is applicable not only to structural alloys, but also to functional alloys. In this paper we have focussed on two materials as examples: high $\mathrm{Cr}$ ferritic steels and hydrogen
\end{abstract} \\ storage alloys.
}

Keywords. Alloy design; molecular orbital method.

\section{Introduction}

Advanced technology necessitates the development of new materials with a variety of functions. In response to this demand of the 21 st century, a theoretical method for alloy design has been developed on the basis of the DV-X $\alpha$ molecular orbital calculations of electronic structures (Morinaga et al 1984a). Following this method, various alloys, including heat-resistant Ni-based single crystal superalloys (Morinaga et al 1984b) and high-strength titanium alloys (Morinaga et al 1992), have been designed and developed successfully without any trial-and-error experiments. In this paper, recent progress in this method will be reviewed focussing on the following two materials: (i) high $\mathrm{Cr}$ ferritic steels for power plant applications and (ii) hydrogen storage alloys for hydrogen energy applications.

\section{DV-X $\alpha$ molecular orbital method}

This method is constructed on the basis of the Hartree-Fock-Slater approximation, using a Slater's $\mathrm{X} \alpha$ potential (Slater 1974). Local electronic structures can be calculated by this method even for a large size of molecule. Depending on the crystal structure, appropriate cluster models are employed in the calculation. For example, a bcc cluster model is shown in figure 1. Here, 'cluster' means a hypothetical molecule to represent a metal crystal. Despite the use of such a small cluster, there is good resemblance in the calculated electron density of states between the band theory and the molecular orbital theory (for example, $\mathrm{Ni}_{3} \mathrm{Al}$ (Morinaga et al 1984a) and bcc Fe (Morinaga et al 1985)).

\section{High $\mathrm{Cr}$ ferritic steels}

\subsection{New alloying parameters}

Two alloying parameters are obtained by the calculation using a cluster model

*Author for correspondence 
shown in figure 1 (Morinaga et al 1985). One is the d-orbital energy level of alloying transition metal in bcc Fe (hereafter referred to as $\mathrm{Md}$ ). The Md parameter correlates with the electronegativity and the atomic radius of elements. The other is the bond order (hereafter referred to as Bo) which shows the strength of the chemical bond between $\mathrm{Fe}$ and $\mathrm{M}$ atoms. It increases with increasing chemical bond strength between atoms. The $\mathrm{Md}$ and Bo values are listed in table 1 for a

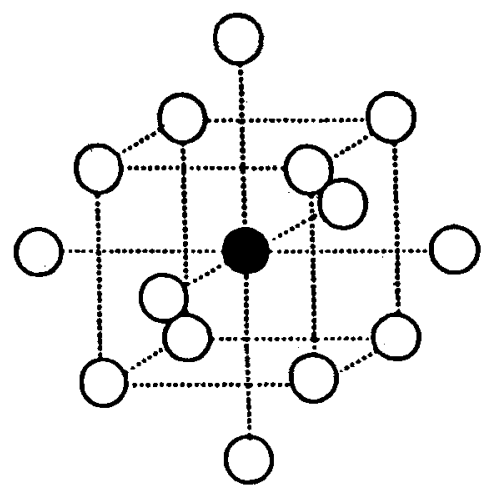

\section{Pe alom \\ Aloying element. M}

Figure 1. Cluster model employed in the calculation.

Table 1. List of Md and Bo values for alloying elements in bcc Fe.

\begin{tabular}{|c|c|c|c|}
\hline \multicolumn{2}{|c|}{ Element } & \multirow{2}{*}{$\frac{M d(\mathrm{eV})}{2.497}$} & \multirow{2}{*}{$\frac{\text { Bo }}{2 \cdot 325}$} \\
\hline \multirow{8}{*}{$3 d$} & $\mathrm{Ti}$ & & \\
\hline & v & 1.610 & 2.268 \\
\hline & $\mathrm{Cr}$ & 1.059 & $2 \cdot 231$ \\
\hline & $\mathrm{Mn}$ & 0.854 & 1.902 \\
\hline & $\mathrm{Fe}$ & 0.825 & 1.761 \\
\hline & Co & 0.755 & 1.668 \\
\hline & $\mathrm{Ni}$ & 0.661 & $1 \cdot 551$ \\
\hline & $\mathrm{Cu}$ & 0.637 & 1.361 \\
\hline \multirow{3}{*}{$4 d$} & $\mathrm{Zr}$ & 3.074 & $2 \cdot 551$ \\
\hline & $\mathrm{Nb}$ & 2.335 & 2.523 \\
\hline & Mo & 1.663 & $2 \cdot 451$ \\
\hline \multirow{4}{*}{$5 d$} & $\mathrm{Hf}$ & $3 \cdot 159$ & 2.577 \\
\hline & $\mathbf{T a}$ & 2.486 & 2.570 \\
\hline & $\mathbf{W}$ & 1.836 & 2.512 \\
\hline & $\operatorname{Re}$ & 1.294 & 2.094 \\
\hline \multirow{3}{*}{ Others } & C & -0.230 & 0 \\
\hline & $\mathbf{N}$ & -0.400 & 0 \\
\hline & $\mathrm{Si}$ & 1.034 & 0 \\
\hline
\end{tabular}


variety of alloying elements in bcc Fe (Morinaga et al 1985). It is important to note here that both of these parameters change periodically following the order of elements in the periodic table.

For an alloy the average value of $\mathrm{Md}$ and $\mathrm{Bo}$ are defined by taking the compositional average, and $\overline{\mathrm{Md}}$ and $\overline{\mathrm{Bo}}$ are denoted as follows.

$$
\begin{aligned}
& \overline{\mathrm{Md}}=\Sigma \mathrm{Xi} \cdot(\mathrm{Md}) \mathrm{i}, \\
& \overline{\mathrm{Bo}}=\Sigma \mathrm{Xi} \cdot(\mathrm{Bo}) \mathrm{i} .
\end{aligned}
$$

Here, $\mathrm{Xi}$ is the atomic fraction of component $\mathrm{i}$ in the alloy, (Md)i and (Bo)i are the respective values for component $i$ as listed in table 1 . The summation extends over the components, $i=1,2, \ldots, n$. For simplicity, the unit of $\overline{\mathrm{Md}}$ parameter, $\mathrm{eV}$, is omitted in this paper.

\subsection{Estimation of alloying behaviour using new parameters}

3.2a Alloying vectors: In figure 2, characteristics of each alloying elements are represented by an alloying vector starting from the position of pure $\mathrm{Fe}$ and ending at the position of $\mathrm{Fe}-1$ at\% $\mathrm{M}$ binary alloy in the $\overline{\mathrm{BO}}-\overline{\mathrm{Md}}$ diagram (Morinaga et al 1994). All the ferrite stabilizing elements (e.g. Cr and Mo) are located in the upper-right region except for $\mathrm{Mn}$, whereas all the austenite stabilizing elements (e.g. $\mathrm{Ni}$ and $\mathrm{Co}$ ) are located in the lower-left region in this diagram. In addition, the direction of alloying vectors is similar among the elements in the same group in the periodic table, for example, $\mathrm{Ti}, \mathrm{Zr}$, $\mathrm{Hf}$ (4A group elements) and $\mathrm{V}, \mathrm{Nb}, \mathrm{Ta}$ (5A group elements). Thus, the Bo and $\mathrm{Md}$ parameters or alloying vectors well reflect the characteristics of elements following their positions in the periodic table.

3.2b $\mathrm{Cr}$ equivalent: The $\mathrm{Cr}$ equivalent ( $\mathrm{Creq}$ ) for ferritic steels may be given by a Newhouse equation,

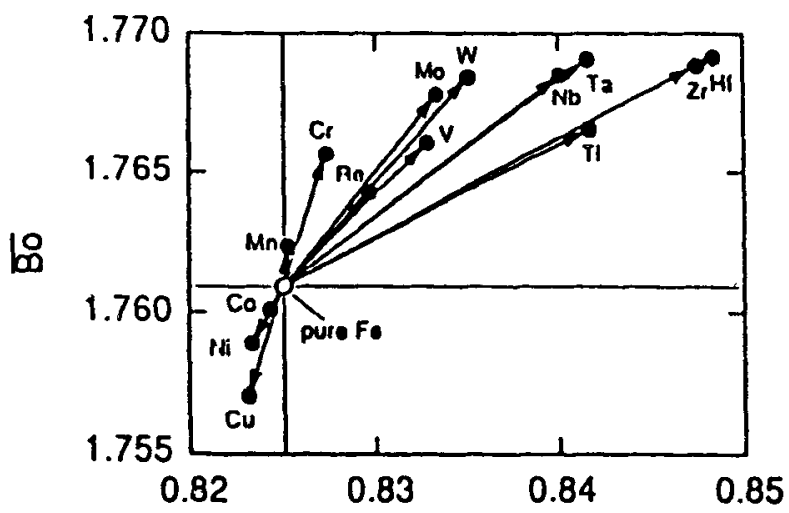

$\overline{\mathrm{Md}}$

Figurc 2. Alloying vectors of elements in bec Fe 


$$
\begin{aligned}
\mathrm{Creq}= & {[\% \mathrm{Cr}]+6[\% \mathrm{Si}]+4[\% \mathrm{Mo}]+1 \cdot 5[\% \mathrm{~W}]+11[\% \mathrm{~V}]+2 \cdot 5[\% \mathrm{Ta}] } \\
& +5[\% \mathrm{Nb}]-(40[\% \mathrm{C}]+2[\% \mathrm{Mn}]+4[\% \mathrm{Ni}]+2[\% \mathrm{Co}]+30[\% \mathrm{~N}])
\end{aligned}
$$

Here, $[\% \mathrm{M}]$ means the weight $\%$ of element $\mathrm{M}$ in the steel. This equation is converted into atomic units in order to compare it with the Md equation expressed in atomic units. The coefficient for each element obtained in this way is comparable to the corresponding Md value as shown in figure 3. Thus, there is a certain relationship between them, although every coefficient in the Newhouse equation has been determined empirically.

$3.2 c \delta$ ferrite formation: It is desirable to suppress the formation of the $\delta$ ferrite in ferritic steels because of its detrimental effect on the creep resistance and the fracture toughness of them. The measured volume fraction of the $\delta$ ferrite existing in the steels normalized at $1323 \mathrm{~K}$ correlates well with the $\overline{\mathrm{Md}}$ parameter as shown in figure 4.

For Ni-free steels the $\delta$ ferrite starts forming as the $\overline{\mathrm{Md}}$ value exceeds 0.852 , and its volume fraction increases with increasing $\overline{M d}$ value. Also, as is evident from this figure, the existence of $\mathrm{Ni}$ atoms in steels increases the critical $\overline{\mathrm{Md}}$ value for the $\delta$ ferrite formation. Generally, austenite stabilizing elements such as $\mathrm{Ni}$, $\mathrm{Co}$ and $\mathrm{Cu}$ could suppress the $\delta$ ferrite formation in steel more effectively than expected from the $\overline{\mathrm{Md}}$ value.

3.2d Creep rupture properties: Here, the presence of the $\delta$ ferrite is shown to be detrimental to the creep rupture properties of ferritic steels. In figure 5, allowable tensile stresses at $873 \mathrm{~K}$ are plotted against the $\overline{\mathrm{Bo}}$ values for various $9-12 \% \mathrm{Cr}$ steels. In this figure $\delta$ ferrite-free steels are indicated by $\bullet$ symbol, and $\delta$ ferrite-prone steels are indicated by $\Delta$ symbol. It is apparent that the allowable tensile stress increases monotonically with increasing $\overline{\mathrm{Bo}}$ value for the $\delta$ ferrite-free steels.

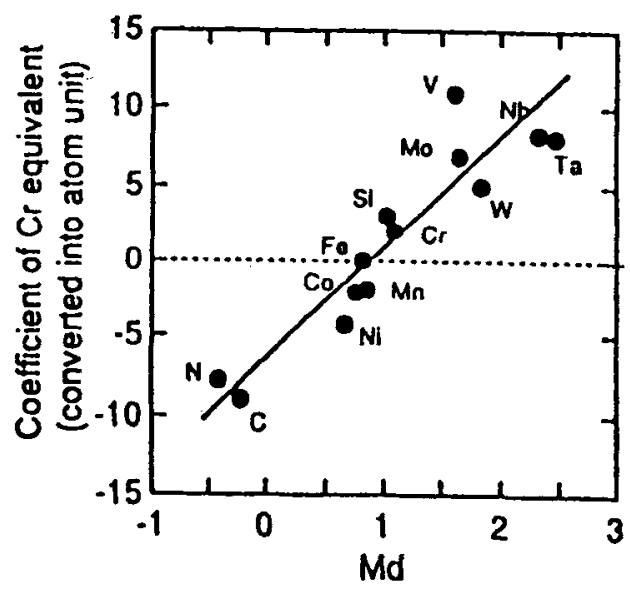

Figure 3. Relation between the Md values and the coefficient of chromium equivalent for each element. 
However, for $\delta$ ferrite-prone steels the stress level is very small even in the case when the $\overline{\mathrm{BO}}$ value is high, indicating that the existence of the $\delta$ ferrite definitely lowers the creep resistance of steels.

\subsection{Trace of the evolution of ferritic steels in the $\overline{B o}-\overline{M d}$ diagram}

For example, $9 \% \mathrm{Cr}$ steels for boilers have been developed in the sequence, $\mathrm{T} 9 \rightarrow(\mathrm{F9}) \rightarrow \mathrm{T} 91 \rightarrow \mathrm{NF616}$. Here, T91 (Mod.9Cr-1Mo) was developed from T9

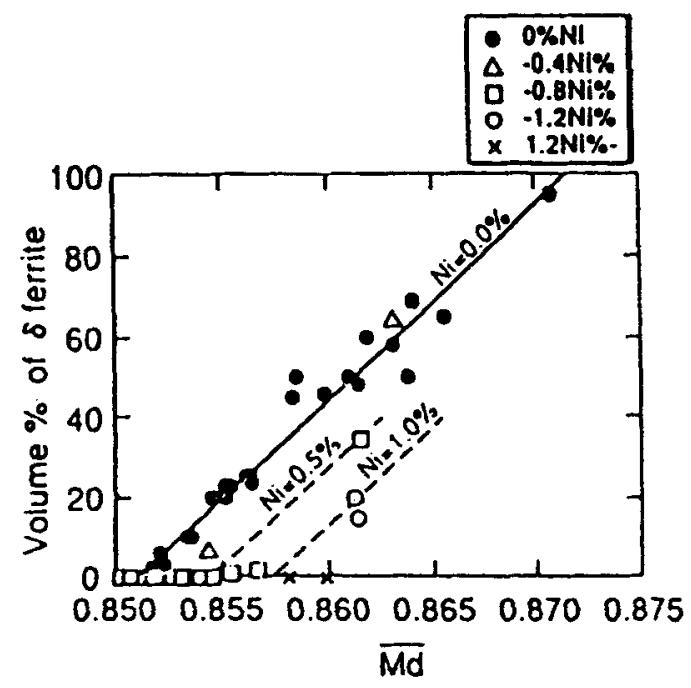

Figure 4. Estimation for the volume $\%$ of $\delta$ ferrite in terms of $\overline{\mathrm{Md}}$.

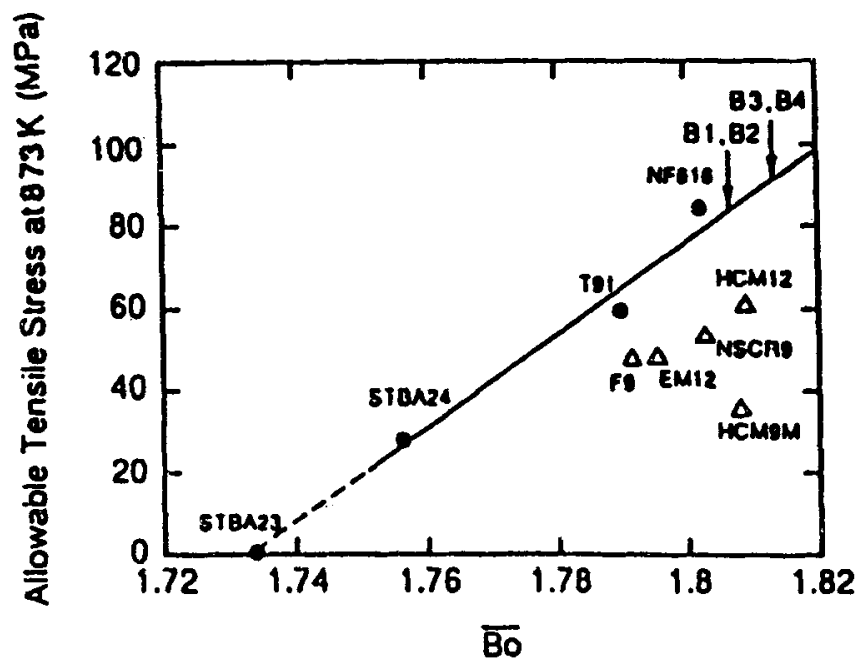

Figure 5. Correlation of the allowable tensile stress at $873 \mathrm{~K}$ with the $\overline{\mathrm{Bo}}$ of $9-12 \% \mathrm{Cr}$ steels. 
( $9 \mathrm{Cr}-1 \mathrm{Mo}$ ) by optimizing the contents of $\mathrm{V}$ and $\mathrm{Nb}$ both of which form carbonitrides and strengthen steels. Then, NF616 was obtained from T91 by reducing the Mo content, but instead increasing the $\mathrm{W}$ content. As shown in figure 6 , this evolution is traceable in the $\overline{\mathrm{Bo}}-\overline{\mathrm{Md}}$ diagram. The evolution, $\mathrm{T} 9 \rightarrow \mathrm{T} 91 \rightarrow \mathrm{NF} 616$, is interpreted as the alloy modification toward the higher $\overline{\mathrm{Md}}$ and the higher $\overline{\mathrm{Bo}}$ in the diagram. The $\overline{M d}$ value of NF616 is about 0.852 , which is nearly the same as the critical $\overline{\mathrm{Md}}$ value for the $\delta$ ferrite formation in the Ni-free steels (see figure 4).

The evolution of the steels for turbine rotors, which have been developed in the sequence, $\mathrm{H} 46 \rightarrow \mathrm{GE} \rightarrow \mathrm{TMK} 1 \rightarrow \mathrm{TMK} 2$, can also be traced in the $\overline{\mathrm{Bo}}-\overline{\mathrm{Md}}$ map as shown in figure 7 . The evolution, GE $\rightarrow$ TMK1 $\rightarrow$ TMK2 is definitely the change

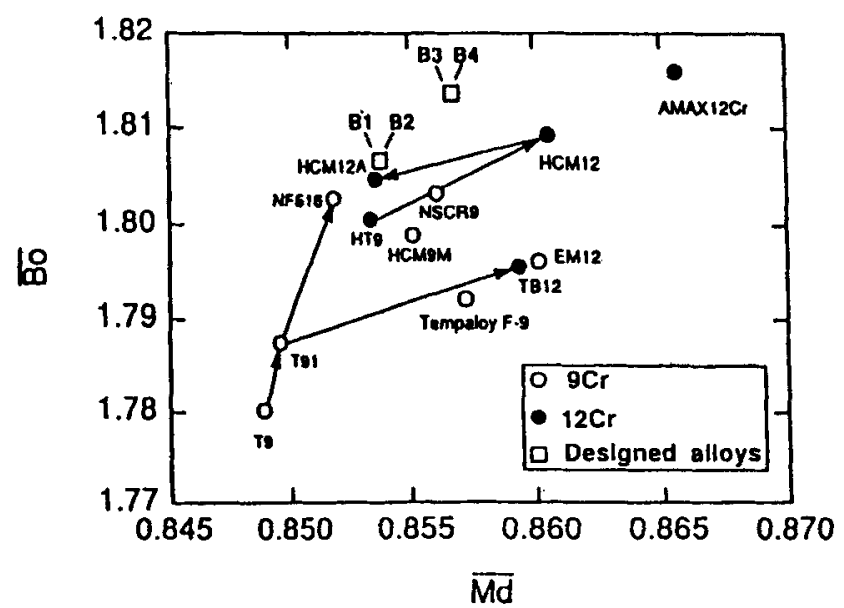

Figure 6. Location of $9-12 \% \mathrm{Cr}$ steels for boilers in the $\overline{\mathrm{Bo}}-\overline{\mathrm{Md}}$ diagram.

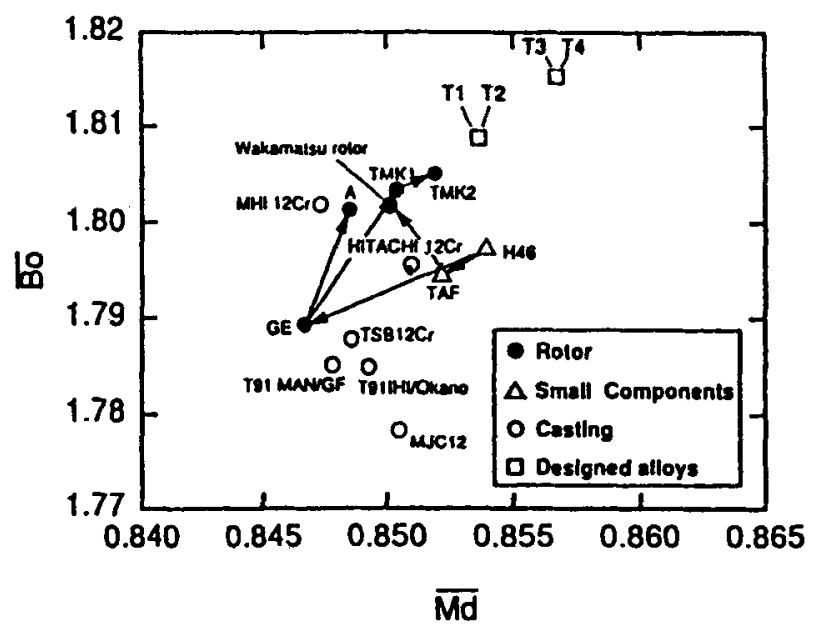

Figure 7. Location of $9-12 \% \mathrm{Cr}$ steels for turbines in the $\overline{\mathrm{Bo}}-\overline{\mathrm{Md}}$ diagram. 
toward the higher $\overline{\mathrm{Md}}$ and higher $\overline{\mathrm{Bo}}$, as is found similarly in the evolution, T9 $\rightarrow$ T91 $\rightarrow$ NF616.

\subsection{Alloy design}

By using $\overline{\mathrm{Bo}}$ and $\overline{\mathrm{Md}}$ parameters together with several empirical rules, a new design has been carried out for ferritic steels for both boiler and turbine rotor applications.

The designed steels for boiler applications are found experimentally to have the better creep resistance than NF616 (Morinaga et al 1994). Also, the steels for turbine rotor applications are superior in many aspects to TMK2 and HR1200 (Hashizume et al 1996).

\section{Hydrogen storage alloys}

Hydrogen storage alloys are one of the key materials for the development of future clean hydrogen energy system. For a variety of materials, alloying effects have been investigated experimentally to improve the hydrogen absorption and desorption characteristics of them. Also, electronic structures have been calculated theoretically. However, despite such great effort, the alloying effect still remains unclear. Here, recent results on $\mathrm{Mg}_{2} \mathrm{Ni}$ (Takahashi et al 1996) will be explained, because this is one of the promising hydrogen storage alloys.

\subsection{Cluster model}

The cluster model used is shown in figure 8. This model is constructed on the basis of the crystal structure of $\mathrm{Mg}_{2} \mathrm{NiH}_{4}$. Here, $\mathrm{Ni}$ and $\mathrm{Mg}$ atoms occupy the

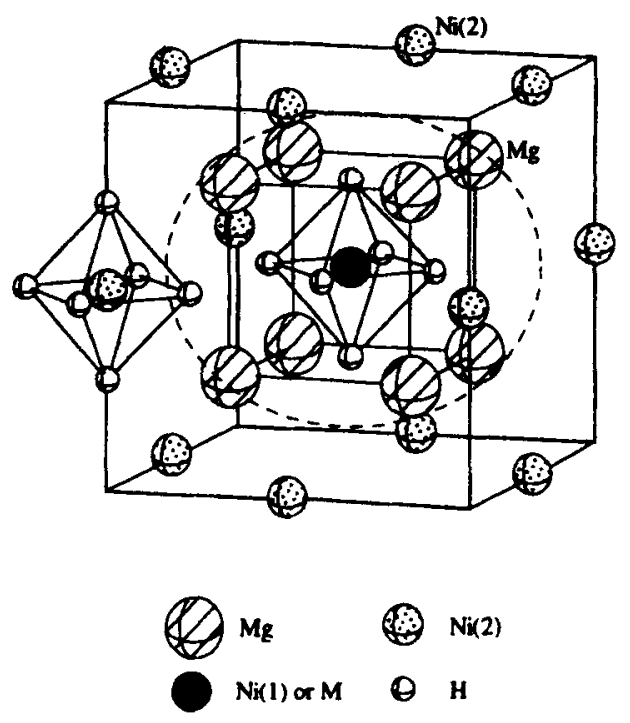

Figure 8. Cluster model used in the calculation. 
cation and the anion sites in the $\mathrm{CaF}_{2}$-type crystal structure, respectively. Each $\mathrm{Ni}$ atom is surrounded by $8 \mathrm{Mg}$ atoms and also by hydrogen atoms sitting on the corners of a small octahedron. In order to examine alloying effects, a central $\mathrm{Ni}$ atom in the cluster is substituted for various alloying elements, $M$.

\subsection{Metal-hydrogen interaction}

A contour map of electron densities is shown in figure 9 for the (110) atomic plane of the $\mathrm{Mg}_{2} \mathrm{Ni}$ system. Relatively high electron density region extends from the $\mathrm{H}$ atom site to the $\mathrm{Ni}$ atom site, but not to the $\mathrm{Mg}$ atom site. This result clearly indicates that the hydrogen atom exhibits a larger affinity with $\mathrm{Ni}$ atoms rather than $\mathrm{Mg}$ atoms in this system, despite the larger affinity of $\mathrm{Mg}$ atoms for hydrogen than $\mathrm{Ni}$ atoms in the binary metal-hydrogen system. This is very important in understanding the easiness of dehydriding characteristic of hydrogen storage alloys, since the relatively weak $\mathrm{Ni}-\mathrm{H}$ interaction can promote the dehydriding process. In other words, if hydrogen atom interacts strongly with $\mathrm{Mg}$ atoms instead of $\mathrm{Ni}$ atoms in the hydride, the dehydriding will not be expected to occur readily in it.

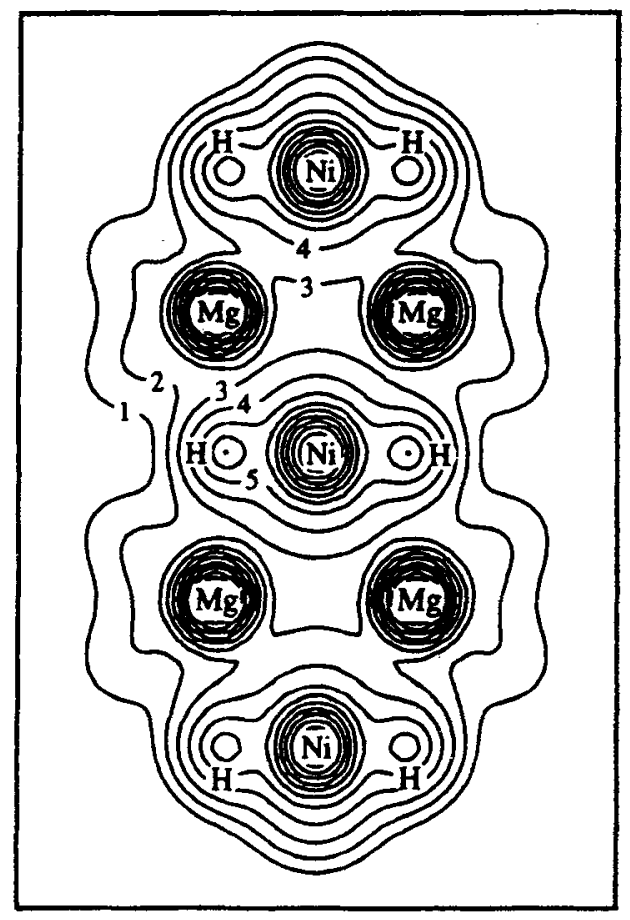

Figure 9. Contour map of the electron density distributions on the (110) atomic plane of $\mathrm{Mg}_{2} \mathrm{Ni}$ hydride. The denoted numbers, $1,2,3,4,5$ and 6 correspond to the electron density values, $0.005,0.01,0.02,0.04,0.08$ and 0.16 in electrons per cube of the atomic unit, respectively. 


\subsection{Alloying effect on the chemical bond between atoms}

The bond order is the overlap population of the electrons between atoms. This is a measure of the strength of the covalent bond between atoms. The changes in the bond order with alloying elements in the $\mathrm{Mg}_{2} \mathrm{Ni}$ system are shown in figure 10. Referred to ' $\mathrm{H}$ ' in this figure are the hydrogen atoms sitting on the corner sites of the octahedron around an alloying element, $M$ (see figure 8). As shown in the figure, the $\mathrm{M}-\mathrm{H}$ bond order is significantly large, indicating that there is an attractive and strong interaction operating between the alloying elements and the hydrogen atom. The magnitude of this bond order changes with $\mathrm{M}$. In response to this change, the $\mathrm{M}-\mathrm{Mg}$ bond order varies in a reverse way. Namely, the alloying elements which have a strong affinity with the hydrogen atom, tend to interact weakly with the surrounding $\mathrm{Mg}$ atoms. In addition, although the $\mathrm{Ni}-\mathrm{Ni}$ bond order is not shown in the figure, it is very small and negative $(\sim-0.001)$ due to the much larger distance between them $(\sim 0.460 \mathrm{~nm})$, as compared to the distance in pure fcc $\mathrm{Ni}(\sim 0.2498 \mathrm{~nm})$. Also, the $\mathrm{Mg}-\mathrm{Mg}$ interaction is very weak.

\subsection{Alloying effect on the hydrogen absorption and desorption characterisics}

As explained above, the metal framework of pure $\mathrm{Mg}_{2} \mathrm{Ni}$ system is held mainly by the $\mathrm{Ni}-\mathrm{Mg}$ interactions. Therefore, as shown in figure 8 , a small cube containing $\mathrm{Ni}$ and $\mathrm{Mg}$ atoms is the important crystal unit to determine the phase stability of this hydride. The atomic interactions in the cube are modified considerably by alloying mainly due to the change in the $\mathrm{M}-\mathrm{Mg}$ interaction with $\mathrm{M}$. The weakening of this interaction causes the instability of the cubic framework. As a result, the stability of the hydride decreases with the decreasing $\mathrm{M}-\mathrm{Mg}$ bond order, even

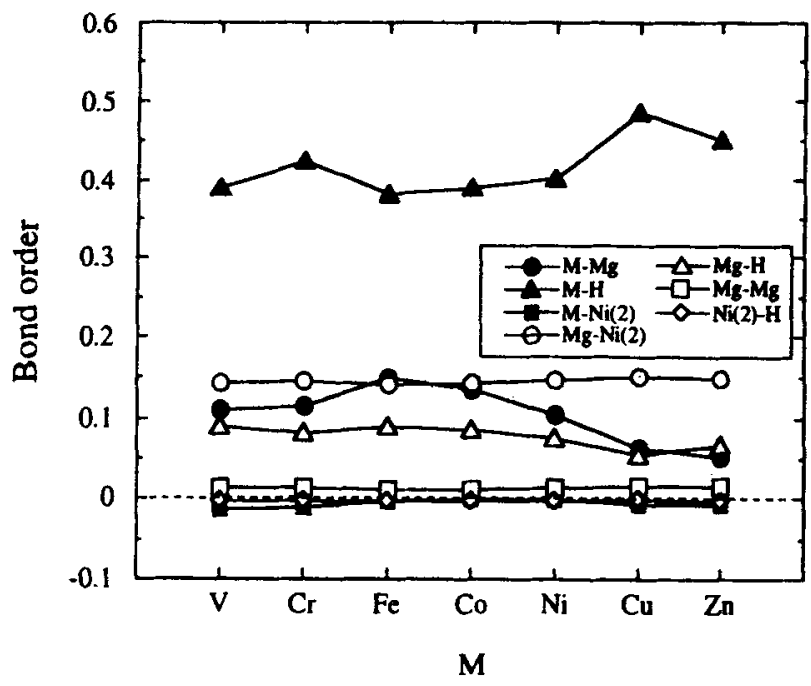

Figure 10. Changes in the bond orders with the $\mathrm{Ni}$ substitutional elements in the $\mathrm{Mg}_{2} \mathrm{Ni}$ system. 


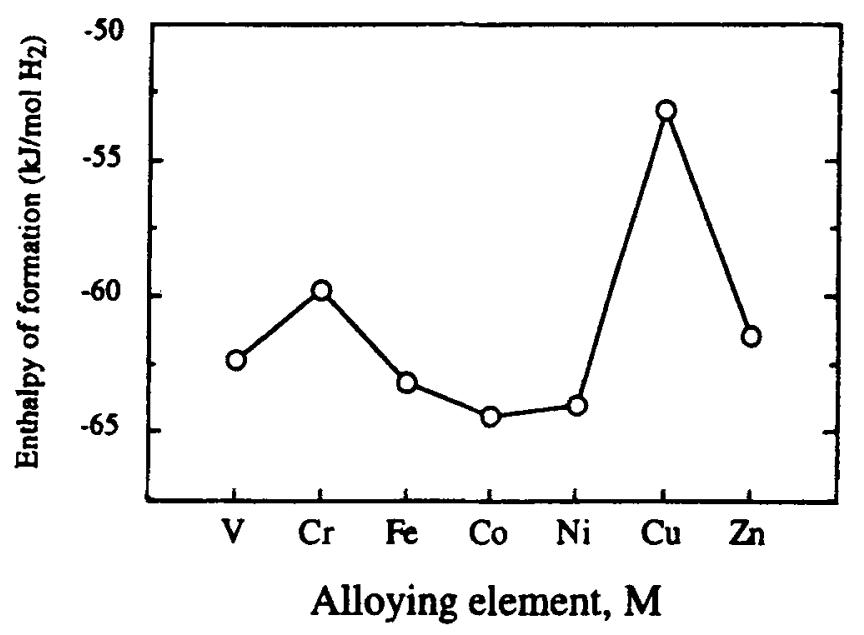

Figure 11. Changes in the enthalpy of formation for the hydrides in $\mathrm{Mg}_{2} \mathrm{Ni}$ system with alloying elements.

though the increasing $\mathrm{M}-\mathrm{H}$ interaction may act to increase the stability of the hydride to some extent. In fact, as shown in figure 11 , the measured enthalpy of formation for the hydrides, $\Delta H$, with alloying elements $(\mathrm{M})$ in $\mathrm{Mg}_{2} \mathrm{Ni}_{0.75} \mathrm{M}_{0.25}$, changes in an approximately reverse way as does the $\mathrm{M}-\mathrm{Mg}$ bond order shown in figure 11. It is also true that the $\Delta H$ curve resemble the $\mathrm{M}-\mathrm{H}$ bond order curve.

The present approach is also useful in understanding experimental results of other hydrogen storage alloys, $\mathrm{LaNi}_{5}$ (Yukawa et al 1996), $\mathrm{CaNi}_{5}, \mathrm{TiFe}$ and $\mathrm{ZrMn}_{2}$. The nature of the chemical bond between atoms neighbouring hydrogen determines the stability of hydrides formed in these alloys (Yukawa and Morinaga 1996).

\section{Conclusion}

The molecular orbital approach is very useful for alloy design to save cost and time necessary for alloy development.

\section{Acknowledgements}

The authors acknowledge the Computer Centre, Institute for Molecular Science, Okazaki National Institute, for the use of the SX-3/34R computer. This research is supported by the Grant-in-Aid for Scientific Research from the Ministry of Education, Science, Sports and Culture of Japan.

\section{References}

Hashizume R, Murata $\mathrm{Y}$ and Morinaga M 1996 CAMP-ISIJ 91321,1322

Morinaga M, Yukawa N and Adachi H 1984a J. Phys. Soc. Jpn 53653 
Morinaga M, Yukawa N, Adachi $\mathrm{H}$ and Ezaki H 1984b Superalloys (eds) M Gell et al (Pennsylvania: The Metallurgical Society of AIME) pp 525-534

Morinaga M, Yukawa N and Adachi H 1985 J. Phys. F: Met. Phys. 151071

Morinaga M, Kato M, Kamimura T, Fukumoto M, Harada I and Kubo K 1992 Proc. of seventh world conf. on titanium, San Diego (TMS) pp 217-224

Morinaga M, Hashizume $\mathrm{R}$ and Murata $\mathrm{Y} 1994$ Materials for advanced power engineering (eds) D Coutsouradis et al (The Netherlands: Kluwer Academic Pub.) pp 319-328

Slater J C 1974 Quantum theory of molecules and solids (New York: McGraw-Hill) Vol. 4

Takahashi Y, Yukawa $\mathrm{H}$ and Morinaga M 1996 J. Alloys Comp. 24298

Yukawa $\mathrm{H}$ and Morinaga M 1996 Proc. of first int. workshop on the DV-Xa method, Debrecen, Hungary (eds) H Adachi et al (New York: Academic Press Inc.)

Yukawa H, Takahashi Y and Morinaga M 1996 Intermetallics 4 S215 